\title{
Correlation with Time Explains the Relationship between Survey Nonresponse and Mass Polarization
}

DOI:

$10.1086 / 709433$

Document Version

Accepted author manuscript

Link to publication record in Manchester Research Explorer

\section{Citation for published version (APA):}

Mellon, J., \& Prosser, C. (2020). Correlation with Time Explains the Relationship between Survey Nonresponse and Mass Polarization. Journal of Politics. https://doi.org/10.1086/709433

\section{Published in:}

Journal of Politics

\section{Citing this paper}

Please note that where the full-text provided on Manchester Research Explorer is the Author Accepted Manuscript or Proof version this may differ from the final Published version. If citing, it is advised that you check and use the publisher's definitive version.

\section{General rights}

Copyright and moral rights for the publications made accessible in the Research Explorer are retained by the authors and/or other copyright owners and it is a condition of accessing publications that users recognise and abide by the legal requirements associated with these rights.

\section{Takedown policy}

If you believe that this document breaches copyright please refer to the University of Manchester's Takedown Procedures [http://man.ac.uk/04Y6Bo] or contact uml.scholarlycommunications@manchester.ac.uk providing relevant details, so we can investigate your claim.

\section{OPEN ACCESS}




\title{
Correlation with Time Explains the Relationship between Survey Nonresponse and Mass Polarization
}

\author{
Jonathan Mellon, University of Manchester
}

Christopher Prosser, University of Manchester

\begin{abstract}
While elite polarization in US politics has been well established, there has been substantial debate about whether US mass opinion has polarized in recent decades. Cavari and Freedman (2018) suggest the apparent polarization of the US public may in part be an artifact of declining survey response rates. Cavari and Freedman argue that declining response rates may have led to only the most politicized —and therefore polarized —respondents being willing to give their opinions. We argue that, while the mechanism posited is plausible, other theoretical models of nonresponse predict no change in nonresponse bias or even declining nonresponse bias, depending on the cause of increased nonresponse. We show that the results of Cavari and Freedman's analysis are spuriously driven by each variable's correlation with time. After accounting for the time correlation there is no evidence that nonresponse bias has inflated our estimates of polarization.
\end{abstract}

Short title: Survey Nonresponse and Mass Polarization

Jonathan Mellon (jonathan.mellon@manchester.ac.uk) is a Hallsworth Fellow in the Department of Politics, University of Manchester, UK. Christopher Prosser (chris.prosser@manchester.ac.uk) is a Presidential Fellow in the Department of Politics, University of Manchester, UK. 
In a recent article, Cavari and Freedman (2018) (henceforth, CF) argue that the apparent polarization of US mass opinion is exaggerated by declining survey response rates. As survey response rates declined, they argue, the composition of survey respondents changed, with only the most politicized — and therefore polarized — citizens being willing to give their opinions. In other words, declining response rates increased nonresponse bias when measuring polarization. We argue that, while the mechanism posited by CF seems initially plausible, alternative theoretical models predict stable or declining nonresponse bias when response rates decline. The results of CF's analysis are spuriously driven by each variable's independent correlation with time. When we take correlation with time into account, we find no evidence that declining response rates have inflated levels of polarization. Additionally, when we use a measure of fieldwork effort in the American National Election Studies (ANES) time series dataset to simulate the effect of declining response rates on polarization from 1980-2016, we find no evidence that lower response rates would have changed conclusions about polarization.

\section{Nonresponse bias and polarization}

The idea that mass polarization might be partially an artifact of differential nonresponse seems plausible at face value. It is well established that surveys over-represent politically interested respondents (Groves, Presser and Dipko, 2004; Keeter et al., 2006; Tourangeau, Groves and Redline, 2010; Mellon and Prosser, 2017), and other research has shown that politically interested respondents are more polarized (Abramowitz and Saunders, 2008). If lower response rates have increased nonresponse bias, ${ }^{\mathrm{i}}$ it seems plausible that lower response rates might result in more polarized survey responses.

However, lower response rates do not automatically translate into higher levels of survey error (Curtin, Presser and Singer, 2000, 2005; Keeter et al., 2006) and it is not clear that lower survey response rates have resulted in increased nonresponse bias. For example, Martinez (2003) showed 
the apparently widening gap (Burden, 2000) between official turnout and turnout in the ANES was attributable to using the incorrect turnout benchmark and the ANES's adoption of panel surveys. More recently, Prosser and Mellon (2018) show a stable gap between reported and actual turnout in British Election Study data despite declining response rates. Additionally, while declining response rates fit well with rising mass polarization in the US, other countries show various trends in mass polarization (e.g. Knutsen, 1998) despite uniformly falling response rates around the world.

To demonstrate that declining response rates do not necessarily increase nonresponse bias, we formalize two theoretical models of survey nonresponse. One way to formalize CF's theory is to see nonresponse as a simple function of political interest and random noise. If the sum of the noise and interest exceed a threshold, a respondent answers the survey. However, a problem with this model is that a significant proportion of the recent increase in survey nonresponse has occurred before potential respondents could find out what the survey topic was-potential survey respondents have stopped answering their phones (Kohut et al., 2012). Our second model of nonresponse sees survey response as a two-stage process—-first potential respondents must answer their phones, and second, those who do answer their phones must agree to take part in the survey. Declining contact rates have been attributed to things that have nothing to do with political interest, such as the increase in the volume of cold-calling and robo-calls, and the adoption of caller ID (Prosser and Mellon, 2018). Although we do not know what determines why — given largely uniform exposure to nuisance calling — some people answer their phones to unknown numbers and others do not, a plausible mechanism is that some kinds of traits vary across individuals making some willing to answer their phones and surveys in general. We refer to such traits collectively as prosociality. ${ }^{\text {ii }}$ Crucially, because prosociality is likely to affect response at both stages, the propensity to respond at the two stages is correlated, and declining response rates can happen either by increasing the threshold for response at the contact stage or by increasing the threshold for response conditional on having been 
contacted.

Using these models, we simulate the effect of nonresponse bias for polarization and show that it can increase, stay stable, or even decrease depending on the cause of declining response rates. We report the simulations in detail in the appendix along with formal descriptions of our models but summarize the results here. First, our simulations show that if response rates fall by increasing the participation threshold, we see an artefactual increase in polarization, in line with CF's argument. Second, when we simulate a decline in response rates driven by an increase in the threshold for respondents at the first stage, falling response rates actually reduce nonresponse bias for mass polarization. This is because some people, whose high political interest would overcome their lack of prosociality if they knew the topic of the survey, are filtered out at the contact stage, before their political interest can play a role. By contrast, a stronger first stage filter tends to remove low interest people who would otherwise have dropped out after they heard the topic of the survey. Low interest respondents who make it past the initial pickup filter are disproportionately prosocial and therefore conditionally more likely to take part in the survey at the second stage. Importantly, all our simulations suggest falling response rates could increase nonresponse bias for prosociality-related variables which correlate with response at both stages. Future research should examine whether data on social trust or political trust are biased by nonresponse.

These simulations are not intended to disprove CF's argument. However, they show that we should not have strong theoretical expectations that the effect of declining response rates on nonresponse bias runs in a particular direction. The adequacy of the empirical analysis is therefore of central importance to whether there is evidence for CF's proposed mechanism.

\section{Survey polarization and spurious correlations}

The central evidence CF present is an analysis of a series of questions asked in Pew surveys between 2004 and 2014 that examines the relationship between the survey response rate and 
partisan polarization, as measured by the absolute Cohen's D coefficient of mean differences between Republican and Democrat respondents' answers to each question. ${ }^{\text {iii }}$ CF group the questions into six policy areas (economy, energy, immigration, civil rights, welfare, and foreign policy) and model each area separately (with the survey as the unit of analysis), additionally controlling for congressional polarization.

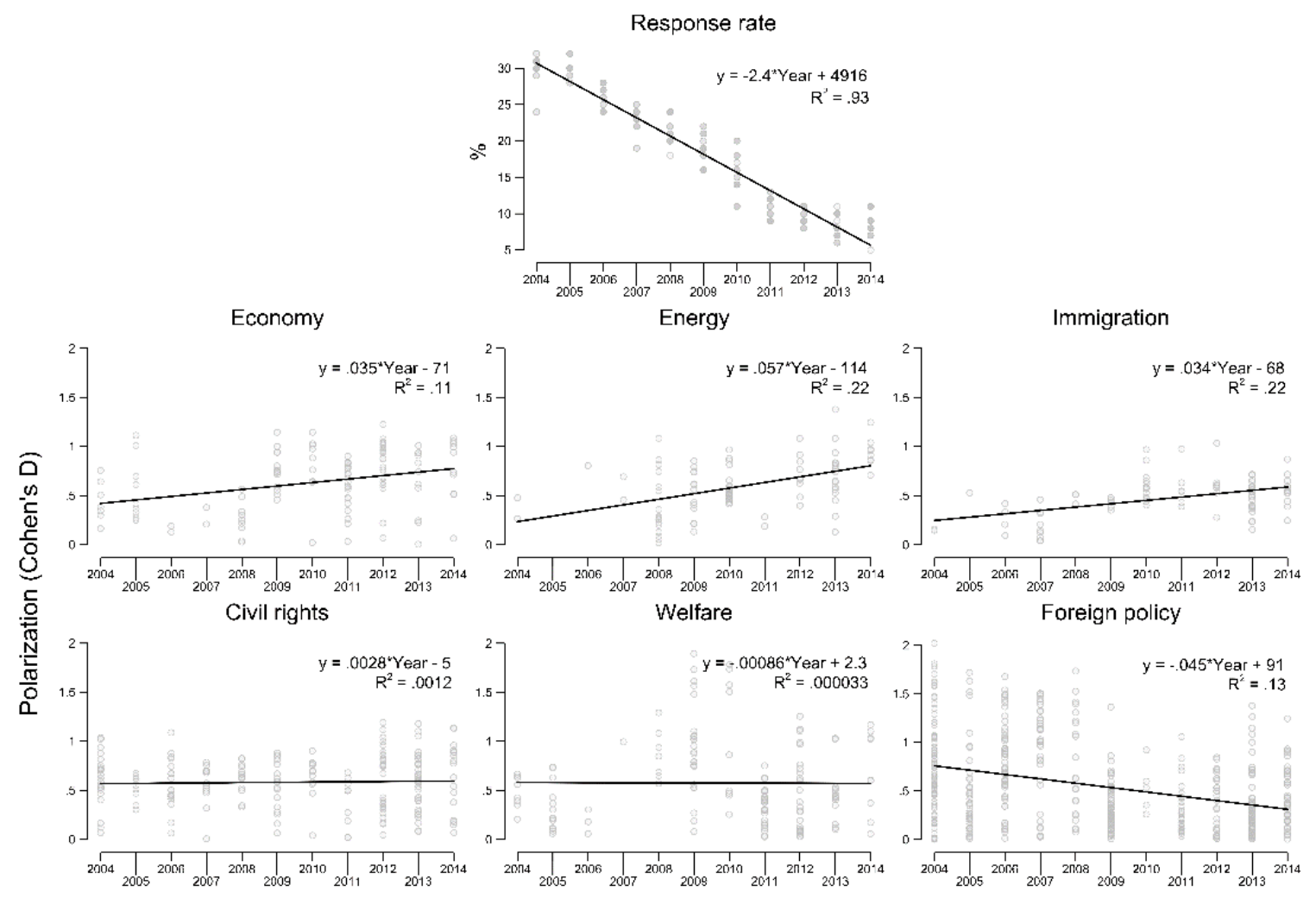

Figure 1. Response rate and dependent variables in Cavari and Freedman's analysis of Pew data over time

CF report statistically significant negative relationships (i.e. lower response rates are associated with more polarization) between response rate and polarization for the economy, energy, and immigration, no relationship for civil rights and welfare (which CF argue attest to the fact that these are longstanding areas of partisan disagreement), and a positive relationship (i.e. lower response rates associated with less polarization) for foreign policy. ${ }^{\text {iv }}$

A potential problem of this model is that it does not take into account the time series nature of the data. Time series data can generate spurious correlations because, as Wooldridge (2009, p. 
360) succinctly describes: "In many cases, two time series processes appear to be correlated only because they are both trending over time for reasons related to other unobserved factors.". This can occur even if two processes are generated by independent random walks (Granger and Newbold, 1974). Analogous problems to spurious correlation appear when pooled models are used to examine time series cross-sectional data without accounting for trends or unit roots (Lebo and Weber, 2015). When we examine CF's data, several key variables are clearly correlated with time. Figure 1 plots the response rate and polarization measures for each of the six policy areas against the year the survey was conducted (along with the linear fit between time and each variable on the plot). Survey response rates declined substantially over this period. The changes over time for polarization look less dramatic but show polarization on the economy, energy, and immigration increased, remained flat for civil rights and welfare, and declined for foreign policy. The results show that response rate is highly correlated with time $\left(\mathrm{R}^{2}=.93\right)$. This strong correlation with time means that survey response rate is likely to be correlated with other variables that are correlated with time, even if they are causally unrelated. We also see statistically significant positive time terms for economy, energy, and immigration, no significant time effects for civil rights and welfare, and a significant negative relationship with time for foreign policy. ${ }^{v}$ If there was no causal relationship between response rate and polarization, because they are both correlated with time, we would expect to see (spurious) negative correlations between response rate, and economy, energy, and immigration, no correlations between response rate, and civil rights and welfare, and a positive correlation between response rate and foreign policy, a pattern that matches CF's findings exactly.

Given the potential problem of spurious correlations between variables because they are both correlated with time, we cannot take the results of CF's model at face value. To address this problem, we build on CF's model in a number of ways. First, we add a linear year term (Wooldridge, 2009), second, we specify a semiparametric model with a nonparametric year function, third, we add 
year fixed effects, and fourth, we add year random intercepts with mean response rate by year included as a covariate. ${ }^{\text {vi }}$ See appendix for the full specifications.

Table 1 shows the results of these analyses. ${ }^{\text {vii }}$ The first set of models replicates CF's original analysis and shows three issue areas with a statistically significant negative relationship between mass polarization and unit response rate: economy, energy, and immigration, and one issue area with a positive relationship between mass polarization and unit response rate: foreign policy.

Once we include a linear time term, all the negative relationships are no longer statistically significant and the coefficients reverse their signs. The one positive relationship found in the original analysis (foreign policy) dramatically shrinks in size and is no longer statistically significant. One issue area, welfare, where no relationship was apparent in the original analysis becomes statistically significant and positively related to response rate. The semiparametric models produce nearly identical results. For both the fixed effects and HLM models, none of the models have statistically significant coefficients, including welfare, suggesting that the statistically significant positive coefficients for welfare in the linear and semiparametric models are also likely to be spurious.

Table 1 Regression models of polarization with and without time controls

\begin{tabular}{|c|c|c|c|c|c|c|}
\hline Time term control & Economy & Energy & Immigration & Civil Rights & Welfare & Foreign Policy \\
\hline None (CF's approach) & $\begin{array}{c}-0.0130^{* * *} \\
(0.00382)\end{array}$ & $\begin{array}{c}-0.0172^{* * *} \\
(0.00430)\end{array}$ & $\begin{array}{c}-0.0169 * * * \\
(0.00352)\end{array}$ & $\begin{array}{c}0.000337 \\
(0.00250)\end{array}$ & $\begin{array}{c}-0.000182 \\
(0.00535)\end{array}$ & $\begin{array}{l}0.0172 * * * \\
(0.00210)\end{array}$ \\
\hline Semiparametric & $\begin{array}{c}0.0121 \\
(0.0137)\end{array}$ & $\begin{array}{l}0.00361 \\
(0.0121)\end{array}$ & $\begin{array}{l}0.00804 \\
(0.0120)\end{array}$ & $\begin{array}{c}0.0119 \\
(0.0106)\end{array}$ & $\begin{array}{c}0.0588^{* *} \\
(0.0180)\end{array}$ & $\begin{array}{l}0.00486 \\
(0.0102)\end{array}$ \\
\hline Year fixed effects & $\begin{array}{l}0.00322 \\
(0.0203)\end{array}$ & $\begin{array}{c}-0.00615 \\
(0.0133)\end{array}$ & $\begin{array}{l}-0.0159 \\
(0.0163)\end{array}$ & $\begin{array}{l}0.00623 \\
(0.0161)\end{array}$ & $\begin{array}{c}0.0327 \\
(0.0218)\end{array}$ & $\begin{array}{l}0.00594 \\
(0.0116)\end{array}$ \\
\hline HLM & $\begin{array}{c}0.0141 \\
(0.0181) \\
\end{array}$ & $\begin{array}{c}-0.00664 \\
(0.0132) \\
\end{array}$ & $\begin{array}{c}-0.00688 \\
(0.0152)\end{array}$ & $\begin{array}{l}0.00837 \\
(0.0150)\end{array}$ & $\begin{array}{c}0.0346 \\
(0.0215)\end{array}$ & $\begin{array}{l}0.00484 \\
(0.0115)\end{array}$ \\
\hline
\end{tabular}

In short, not a single one of CF's original findings is robust to the inclusion of any of a variety of ways of controlling for a time term, leading us to conclude that CF's analysis provides no 
evidence for the effect of response rates on apparent mass polarization in either direction.

We cannot draw strong conclusions from this null, however, because the design is underpowered after accounting for a linear time term. If CF's data generating model is correct, models including a linear time term would have less than 30\% power (see appendix), but if the relationship was spurious, we would find false positives more than $95 \%$ of the time. In short, these data tell us nothing either way about the effect of response rate on polarization.

\section{Simulating lower ANES response rates}

To test CF's theory, we instead use individual-level data from the ANES. We simulate the effect of lower response rates to the ANES by using paradata on fieldwork effort (the number of calls it took before the respondent took part in the survey) to estimate what effect lower survey response rates would have (following the approach of Sturgis et al. (2017)). The logic of this simulation is that the hardest to reach respondents would be the least likely to respond if the overall response rate was lower.

For each Presidential election year from 1980 onwards (excluding 2012 where the paradata is missing), we simulate a response rate decline by converting the number of calls variable within each survey to a percentile, and dropping respondents above a threshold. The threshold starts at 100 in 1980 (all respondents) and declines by 10 percentage points at each Presidential election (e.g. 90 in 1984), reaching 10 in 2016 (the distribution of calls within each survey is skewed, so the proportion included in the sample differs from the threshold in some years). This approach simulates a dramatic decline in response rates, from 71\% in 1980 to 15\% in 2016 (see appendix Figure 5).

We then compare polarization (using CF's Cohen's D approach) in the full ANES sample and our simulated low response rate sample using the six questions CF use in their descriptive analysis (see appendix for question wordings) in Figure 2. If declining response rates exaggerated mass polarization, we would expect to see the simulated low response rate sample become more polarized 
than the actual ANES sample. Instead, the two lines are remarkably similar, with entirely overlapping confidence intervals in every case. In short, the analysis provides no evidence to suggest declining response rates would have inflated our estimates of mass polarization in the ANES.

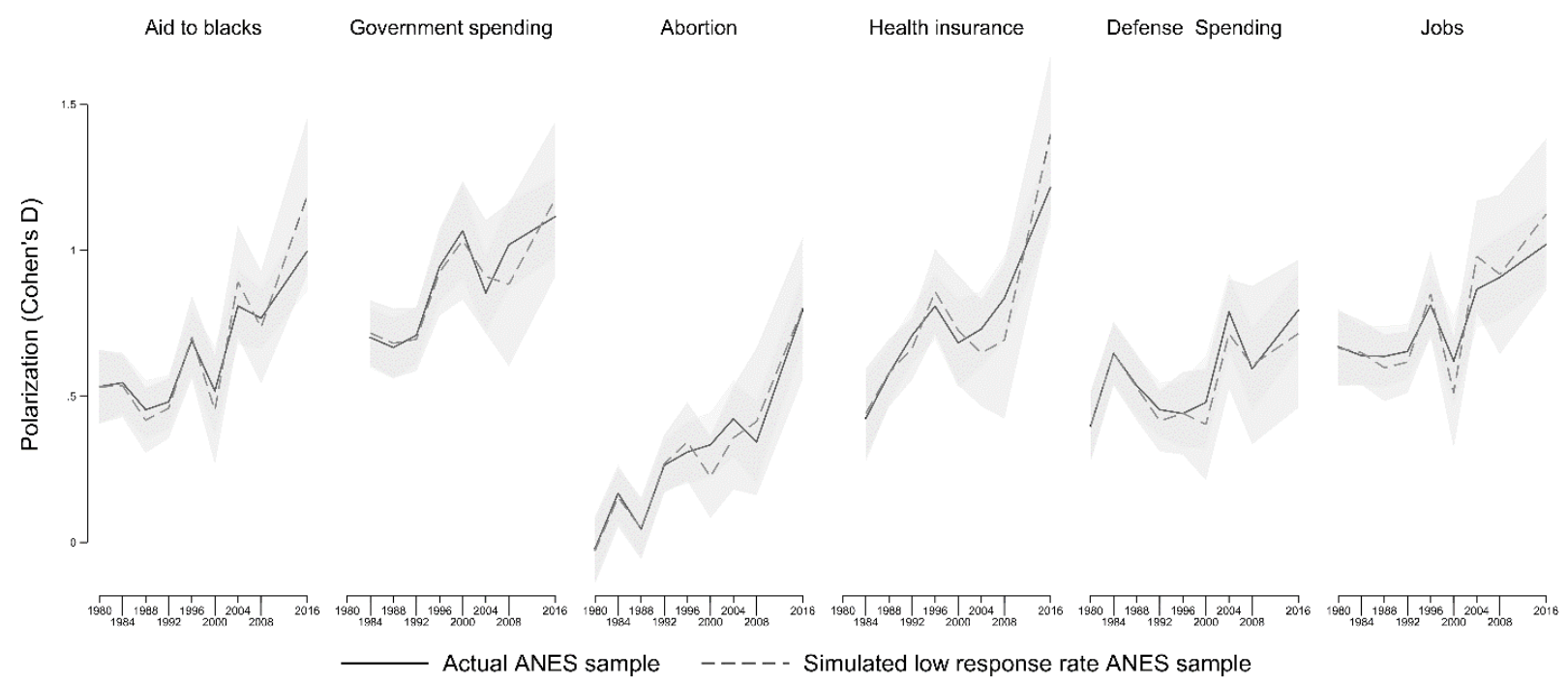

Figure 2. Polarization in the full and simulated response rate decline sample ANES 1980-2016

\section{Conclusions}

The extent to which the American public has polarized is an important question. Survey nonresponse bias is a serious threat to statistical inference. However, our simulations show that falling response rates do not necessarily increase nonresponse bias for variables related to political interest such as polarization. CF argue nonresponse bias has inflated levels of mass polarization but did not account for the fact that both these variables are correlated with time. Accounting for this removes the apparent relationship between response rate and polarization. Correctly specified models do not have sufficient power to rule out a relationship between response rates and polarization. However, we also show an analysis of ANES data that finds no evidence to suggest lower response rates would have inflated levels of polarization. In short, we find no evidence for an effect of survey response rates on the measurement of mass polarization.

\section{References}


Abramowitz, A. I. and Saunders, K. L. (2008) 'Is polarization a myth?', Journal of Politics, 70(2), pp. 542-555.

Bafumi, J. and Gelman, A. (2007) Fitting Multilevel Models When Predictors and Group Effects Correlate, SSRN.

Brüggen, E. and Dholakia, U. M. (2010) 'Determinants of Participation and Response Effort in Web Panel Surveys', Journal of Interactive Marketing, 24(3), pp. 239-250.

Burden, B. C. (2000) 'Voter Turnout and the National Election Studies', Political Analysis. Cambridge University Press, 8(04), pp. 389-398.

Cavari, A. and Freedman, G. (2018) 'Polarized Mass or Polarized Few? Assessing the Parallel Rise of Survey Nonresponse and Measures of Polarization', The Journal of Politics, 80(2).

Cheng, A., Zamarro, G. and Orriens, B. (2016) 'Personality as a Predictor of Unit Nonresponse in Panel Data: An Analysis of an Internet-Based Survey', Ssm.

Curtin, R., Presser, S. and Singer, E. (2000) 'The effects of response rate changes on the index of consumer sentiment.', Public opinion quarterly, 64(4), pp. 413-28.

Curtin, R., Presser, S. and Singer, E. (2005) 'Changes in telephone survey nonresponse over the past quarter century', Public Opinion Quarterly, 69(1), pp. 87-98.

Granger, C. W. J. and Newbold, P. (1974) 'Spurious regressions in econometrics', Journal of Econometrics, 2(2), pp. 111-120.

Groves, R. M., Presser, S. and Dipko, S. (2004) 'The role of topic interest in survey participation decisions', Public Opinion Quarterly, pp. 2-31.

Keeter, S. et al. (2006) 'Gauging the impact of growing nonresponse on estimates from a national RDD telephone survey', Public Opinion Quarterly, 70(5), pp. 759-779.

Knutsen, O. (1998) 'The Strength of Partisan Component of Left-Right Identity', Party Politics, 4(1), pp. $5-31$. 
Kohut, A. et al. (2012) Assessing the Representativeness of Public Opinion Surveys, Pew Research Center.

Lebo, M. and Weber, C. (2015) 'An Effective Approach to the Repeated Cross-Sectional Design', American Journal of Political Science, 59(1), pp. 242-258.

Martinez, M. D. (2003) 'Comment on "Voter Turnout and the National Election Studies"”, Political Analysis, 11(02), pp. 187-192.

Mellon, J. and Prosser, C. (2017) 'Missing Nonvoters and Misweighted Samples: Explaining the 2015 Great British Polling Miss', Public Opinion Quarterly, 81(3), pp. 661-687.

Prosser, C. and Mellon, J. (2018) 'The Twilight of the Polls? A Review of Trends in Polling Accuracy and the Causes of Polling Misses', Government and Opposition.

Rogelberg, S. G. et al. (2003) 'Profiling Active and Passive Nonrespondents to an Organizational Survey', Journal of Applied Psychology, 88(6), pp. 1104-1114.

Sturgis, P. et al. (2017) 'Fieldwork effort, response rate, and the distribution of survey outcomes', Public Opinion Quarterly. Narnia, 81(2), pp. 523-542.

Tourangeau, R., Groves, R. M. and Redline, C. D. (2010) 'Sensitive topics and reluctant respondents: Demonstrating a link between nonresponse bias and measurement error', Public Opinion Quarterly, 74(3), pp. 413-432.

Wooldridge, J. M. (2009) Introductory Econometrics: A Modern Approach. Cengage Learning.

${ }^{i}$ We only consider nonresponse bias for variables linked to political interest such as polarization here.

ii This theory fits with studies finding that prosocial personality traits such as conscientiousness (Rogelberg et al., 2003; Cheng, Zamarro and Orriens, 2016) and agreeableness (Rogelberg et al., 2003; Brüggen and Dholakia, 2010) predict higher survey response rates. However, other traits such as loneliness might also be predictive of response at both stages. iii Cavari and Freedman also conduct some analysis on the ANES. It shows polarization has increased on all issues examined except defense spending and that unit responses rate have declined. There is no modelling of this relationship, so it merely constitutes a re-expression of the original question rather than evidence for the relationship between these phenomena one way or the other.

iv $\mathrm{CF}$ say this is consistent with their theory because Americans are less knowledgeable about foreign policy.

v Augmented Dickey-Fuller (ADF) tests of the annual means of each of these variables suggests only civil rights is a stationary process. However, the 136 Pew surveys in CF's data only cover 11 years (with no further time granularity available) so the ADF test does not have high power to reject the null of non-stationarity, so we see these results as 
indicative rather than conclusive. However, the significant relationship with time when using the survey as the unit of analysis is a clear indication of time heterogeneity in the data.

vi We include mean response rate by year to guarantee conditional independence of random and fixed effects components of the hierarchical linear model (Bafumi and Gelman, 2007),

vii For reasons of space we only show the results of the coefficient for response rate. 